\title{
Design of a micro-channel reactor for decomposition of organic pollutants in waste water treatment
}

\author{
G. Charles, S. Corbel, M-C. Carré, T. Roques-Carmes, O. Zahraa \\ Département de Chimie Physique des Réactions, UMR 7630 CNRS-INPL, Nancy-Université, 1 rue \\ Grandville, BP 20451, 54001 Nancy Cedex, France
}

\begin{abstract}
Photocatalytic micro-channel reactor was built by using stereolithography process. A reactor with a micro-channel as a support of $\mathrm{TiO}_{2}$ photocatalyst was designed in order to reduce dimensions while improving the efficiency. Photocatalytic activity of the micro-reactor at various flow rates was evaluated by the inlet and outlet concentrations of salicylic acid as a model of pollutant. Influence of the initial pollutant concentration, the irradiation intensity on the rate of degradation of the pollutant was studied. A model with the kinetic parameters for the given support geometry was applied to reactor design and scale-up.
\end{abstract}

\section{INTRODUCTION}

Methods, such as photochemical treatments, were envisaged for detoxification of the water and air. Among them, photocatalysis is efficient with the advantage of oxidizing most contaminants of water (fertilizers, pesticides, dyes, ...) until their complete destruction (mineralization) (Avila et al, 1998) with no selective transfer of the pollutants and products on the surface of adsorbent. It uses the inexpensive and available UV-A light as sources of irradiation as well as the water and oxygen as oxidizing agents (Hermann et al, 1999).

The simplest processes are the fluidized bed $\mathrm{TiO}_{2}$ (this poses problems of cost particularly during the stage of separation after purification) or the tubular reactor with catalyst deposited on the walls of reactor, suffering sometimes of limitation of transfer of matter or non homogeneous irradiation. Among the possible solutions for intensification of photocatalytic reactions there is the use of micro-reactors (Van Gerven et al, 2007).

The design and manufacture of micro-reactors by the process of stereolithography, authorizes the fabrication of complex forms with a great flexibility.

The first step of the research has concerned the design and manufacture of a catalytic support whose characteristics are:

- a capacity to overcome the mass transfer,

- the largest ratio of surface on volume in order to obtain a great contact of the pollutant with the catalyst,
- the most important homogeneous irradiation on the whole surface of the structure.

The second step has focused on the study of the influence of geometric characteristics of the support (depth, width, length) on the photocatalytic activity.

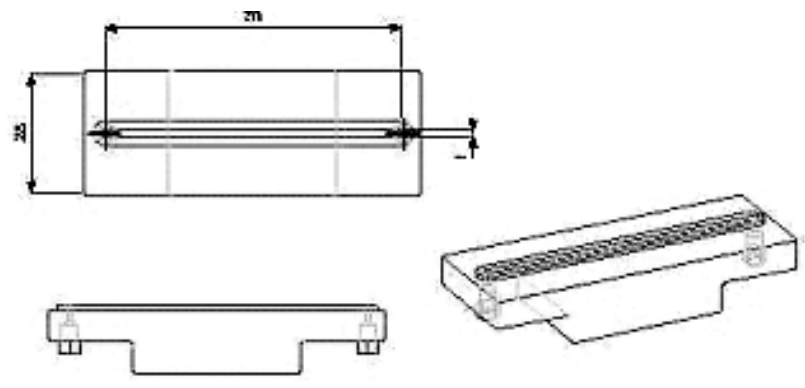

Figure 1. Schematic view of the micro-reactor designed by CAD system; a) Front view; b) side view; c) perspective view.

\section{EXPERIMENTAL}

The micro-channel reactor with the geometry shown on the Figure 2 has been made in epoxy resin (SI 30) by a self-made stereolithography apparatus using a UV Nd-YAG laser (Corbel et al, 2008). 


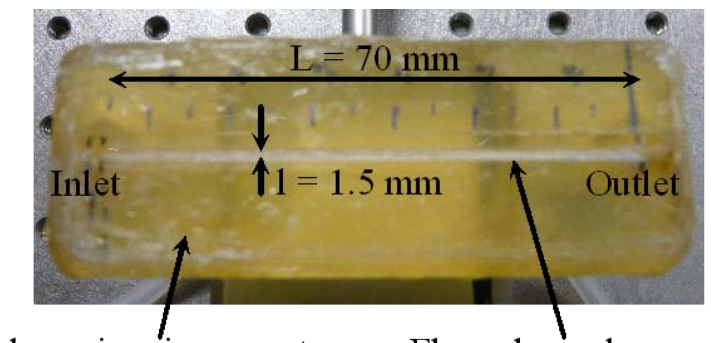

Polymeric micro-reactor Flow channel covered overlaid with a glass slide with a thin $\mathrm{TiO}_{2}$ film

Figure 2. Photographic view of the polymeric micro-reactor. The surface of the channel was coated with a $\mathrm{TiO}_{2}$ thin film by filling it with an acidic aqueous suspension of $\mathrm{TiO}_{2}(4 \mathrm{~g} / \mathrm{L}$; adjusted to $\mathrm{pH} 3$ by addition of nitric acid). After drying at room temperature, the surface load was $20 \mathrm{mg} / \mathrm{cm}^{2}$, this value being above the minimal load generally required for complete light absorption

The experimental setup used for the photocatalytic tests is shown on Figures 3 and 4.

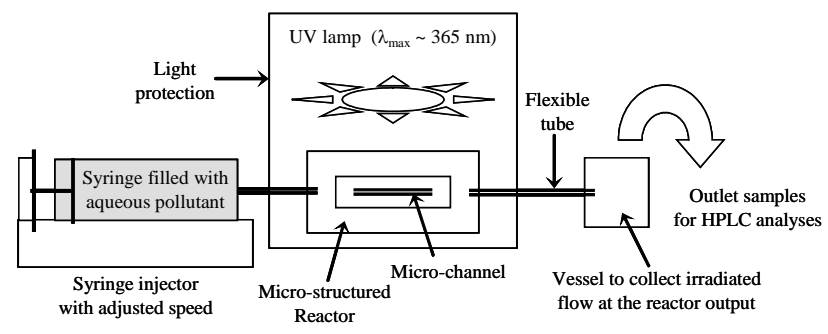

Figure 3. Schematics of the experimental set-up for the degradation in the micro-reactor.

A flow of water containing the pollutant is injected with a syringe at a low speed into the microstructured reactor. An UV fluorescent lamp (Philips, light power $3 \mathrm{~W}, 56 \mathrm{~cm}$ long, $\lambda_{\max } \approx 365 \mathrm{~nm}$ ) located at $1 \mathrm{~cm}$ above the reactor. The incident light power was recorded by a UV radiometer whose spectral response is centered at $365 \mathrm{~nm}$ with a half band-width of $12 \mathrm{~nm}$. The value of $2.8 \mathrm{~mW} / \mathrm{cm}^{2}$ was fixed at the surface of the catalyst. A flexible tube at the outlet of the reactor allows the collect of the irradiated solution samples.

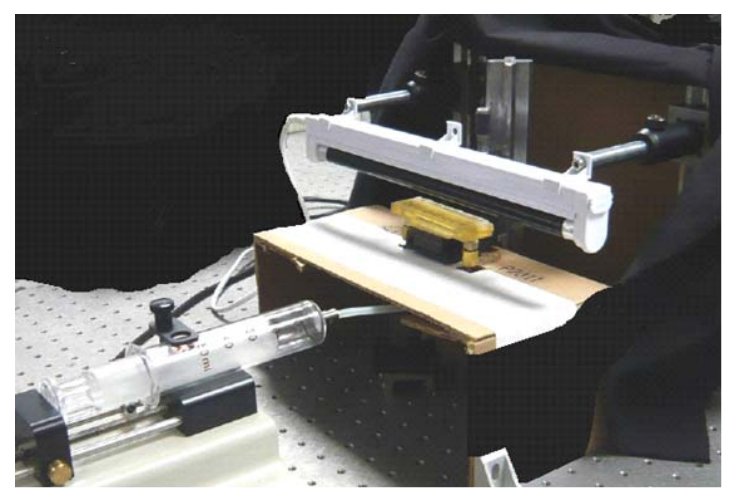

Figure 4. Experimental setup for Photocatalytic reaction with a micro-reactor and syringe used for the injection of the aqueous salicylic acid solution.

In order to validate the micro-structured reactor in a photocatalytic reaction, we have chosen salicylic acid (SA) as model molecule previously studied in the laboratory (Ould-Mame et al., 2000). Its concentration after photoreaction was measured by HPLC with conditions already described. Briefly, the HPLC system is equipped with a variable Shimadzu SPD-20A UV-Vis detector, a Rheodyne Model 7725 injector, a loop size of $20 \mu \mathrm{L}$ and a Shimadzu LC20AT pump. Reverse-phase chromatographic analysis using a Lichrosorb RP-18 column (250 x $4.6 \mathrm{~mm}$ i.d., particle size $5 \mu \mathrm{m}$, Supelco-Inc) was carried out at $25^{\circ} \mathrm{C}$, under isocratic conditions (mobile phase consisted of a mixture of methanol and water containing $0.1 \%$ volumic of phosphoric acid; $70: 30$, v/v; $1 \mathrm{~mL} / \mathrm{min})$. The column effluent was monitored at $\lambda$ $=295 \mathrm{~nm}$. Data acquisition was performed using a Varian System (Star Data Acquisition Workstation, System Control Version 5-52).

\section{RESULTS AND DISCUSSION}

\subsection{Photocatalytic degradation of salicylic acid}

The efficiency of the monolithic photocatalyst was carried out by estimating the degradation rate $\mathrm{R}$ in salicylic acid per volume of reactor $\left(\mathrm{mg} / \mathrm{min} / \mathrm{cm}^{3}\right)$ at different flow rates and inlet concentration of salicylic acid.

$$
R=\frac{Q_{0} C_{0} d X}{d V}
$$

where $\mathrm{Q}_{0}=$ flow rate in $\mathrm{mL} / \mathrm{min} ; \mathrm{dX}=$ experimental conversion of salicylic acid during its contact with the catalyst into the apparent elementary reactor volume $\mathrm{dV}\left(\mathrm{cm}^{3}\right)$.

The results of photocatalytic degradation carried out with the micro-reactor described previously, will be presented as. the variation of the outlet concentration of salicylic acid $\mathrm{C}_{\text {out }}$, obtained at variable flow rate $\mathrm{Q}_{0}$, for a constant inlet concentration $\mathrm{C}_{0}$.

The value of inlet concentration is $10 \mathrm{mg} / \mathrm{L}$ in salicylic acid, and among the geometries tested, we have characterized the performance of the reactor with a $0.5 \mathrm{~mm}$ depth channel.

\subsection{Modelling photocatalytic reaction with Langmuir-Hinshelwood model (LH)}


In photocatalytic studies, the kinetics of photocatalytic degradation is generally represented by the Langmuir-Hinshelwood (LH) model. The reaction rate $\mathrm{R}$ is defined by the following relationship

(Zahraa et al., 2003).

$R=k \frac{K C}{1+K C}$

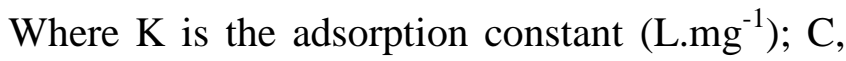
the concentration of salicylic acid in the liquid-phase (mg. $\mathrm{L}^{-1}$ ) and $\mathrm{k}$, an apparent kinetic constant $\left(\mathrm{mg} \cdot \mathrm{min}^{-1} \cdot \mathrm{L}^{-1}\right)$. It is also noticeable that the rate is expressed per unit of reactor apparent volume. The importance of substrate pre-adsorption on a given photocatalyst can be evaluated by the use of a $\mathrm{LH}$ kinetic model, considering that the adsorption of reaction intermediates and products is not significant. In our case, the disappearance of the pollutant during the photocatalytic process has been followed. Then, if photoreactor considered close to a Plug Flow Reactor (PFR), and a constant flow rate (permanent regime) therefore the mass balance through it is given by the following equation:

$\frac{d X}{d V}=\frac{R}{Q_{0} C_{0}}$

with $\mathrm{X}$ conversion within the section volume $\mathrm{dV}$ of the reactor, where $\mathrm{dX}=-\mathrm{dC} / \mathrm{C}_{0}$, then :

$\mathrm{R}=\frac{-Q_{0} d C}{d V}$

from of equations (2) and (4) it can be found:

$\frac{-Q_{0} d C}{d V}=k \frac{K C}{1+K C}$

Where $\mathrm{dV}$ is the elementary volume of the reactor, $\mathrm{Q}_{0}$, the volumetric flow rate. The integration of Eq. (5) is possible only when there is no limitation by mass transfer, no difference of concentration between bulk flow and the catalyst surface (Furman et al, 2007, Dingwang et al, 2001). By integrating equation (5) between the reactor inlet and outlet, it follows:

$\frac{1}{k K} \ln \left(\frac{C_{\text {out }}}{C_{0}}\right)+\frac{1}{k}\left(C_{\text {out }}-C_{0}\right)=-\frac{V}{Q_{0}}$
Eq. (6) can be written introducing the pollutant conversion $\mathrm{X}=1-\mathrm{C}_{\text {out }} / \mathrm{C}_{0}$ :

$\frac{1}{k K} \frac{\ln (1-X)}{C_{0} X}-\frac{1}{k}=-\frac{V}{Q_{0} C_{0} X}$

A plot of $-V /\left(Q_{0} C_{0} X\right)$ versus $\ln (1-X) /\left(C_{0} X\right)$ should be linear and will allow the determination of two constants $\mathrm{k}$ and $\mathrm{K}$. From this optimization, the values of $\mathrm{k}$ and $\mathrm{K}$ obtained are respectively $2.6610^{-5}$ mmol. $\mathrm{min}^{-1} \cdot \mathrm{cm}^{-2}$ and $25 \mathrm{mmol}^{-1} \cdot \mathrm{mL}$.

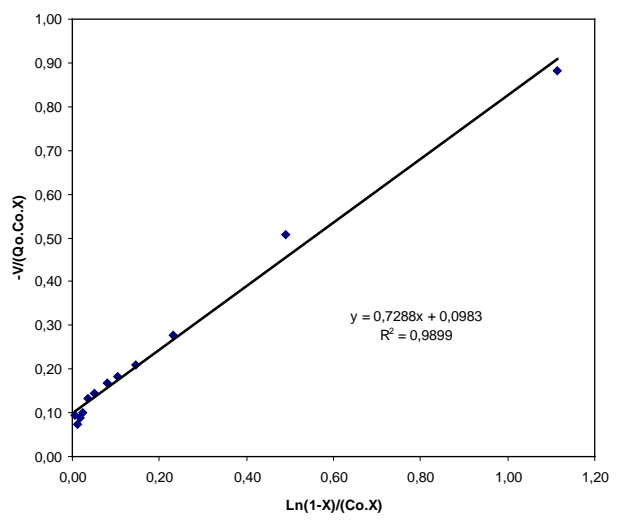

Figure 5. Determination of $\mathrm{k}$ and $\mathrm{K}$ constants from equation (7).

\subsection{Effect of the contact time}

The effect of contact time on salicylic acid (SA) outlet concentrations was investigated in the range of $0.06 \mathrm{~min}$ to $6.33 \mathrm{~min}$. Figure 6 shows that pollutant outlet concentration decreases according to the contact time $\tau=V / \mathrm{Q}_{0}$.

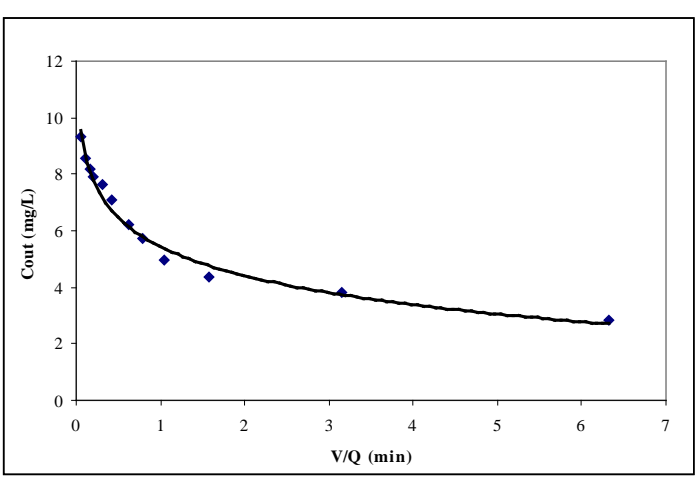

Figure 6. Effect of contact time on the outlet concentration of salicylic Acid. 
It has to be noticed that, the effect of the contact time of reactant was studied by varying the volumetric flow rate with a constant concentration of SA. Figure 7 shows that SA conversion increased first rapidly as the contact time increased in the first minutes then slowly until 6.0 minutes. This behavior has been obtained at approximately high concentration where the rate is independent of concentration (zero order kinetic). It can be noticed that the photocatalytic degradation rate is independent of contact time (or volumetric flow rate) in the first part of the curve.

\subsection{Influence of the light Intensity}

The light flux has been varied by changing the fluorescent lamp and irradiation at two power intensities: $2.8 \mathrm{~mW} / \mathrm{cm}^{2}$ and $0.3 \mathrm{~mW} / \mathrm{cm}^{2}$ (Figure 7).

The influence of the irradiation is clear and the conversion increases a little bet at higher irradiation.

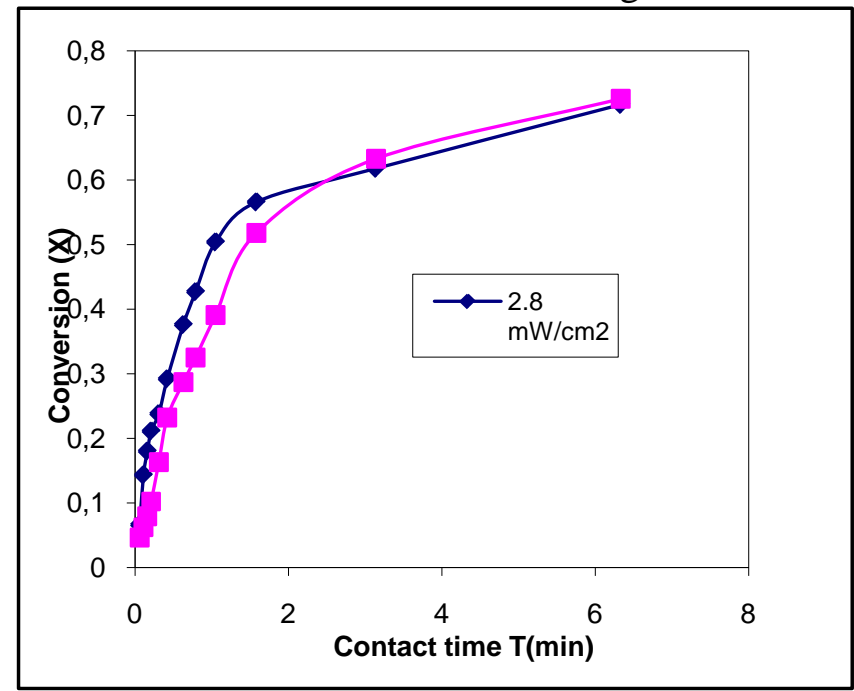

Figure 7. Influence of the Irradiation parameter on the efficiency of the salicylic acid degradation.

\section{CONCLUSION}

The photocatalytic activity of a micro-reactor has been tested in this study. The experiments have been performed in order to determine, how the geometry influences reaction rate, mass transfer rate and finally the photocatalytic efficiency. It has been shown that the geometry influences the kinetic constant $\mathrm{k}$.

As a consequence, the perspective is the development of a geometry having a great ratio surface to volume. At the same time, a very good accessibility of the photons to the catalytic surface must be achieved.

Besides, the optical properties of the polymer show that the support is not inert since it absorbs the light and probably leads to a decrease of the reactivity. That is why the use of another material transparent to the UV light, and able to promote favorable interaction with the pollutant will be developed in the future.

\section{Acknowledgements}

This work was supported in part by grants of the "Region de Lorraine".

\section{REFERENCES}

Avila, P., Bahamonde, A., Blanco, J., Sanchez, B., Cardona, A.I, Romero, M. 1998. Gas-phase photo-assisted mineralization of volatile organic compounds by monolithic titania catalysts. Applied Catalysis : Environmental 17: 75-88.

Corbel, S., Evenou, F., Baros, F., Martinet, N., Donner, M., Carré, M-C. 2008. Micro-structured reactors designed by stereolithography and characterized by fluorescent probes. Hindawi Publishing Corporation International Journal of Photoenergy Article ID 757510, 7 pages, doi:10.1155/2008/757510.

Dingwang C., Fengmei L., Ajay K. Ray 2001. External and internal mass transfer effect on photocatalytic degradation. Catalysis Today 66: 475-485.

Furman, M., Corbel, S., Le Gall, H., Zahraa, O., Bouchy, M. 2007. Influence of the geometry of a monolithic support on the efficiency of photocatalyst for air cleaning. Chemical Engineering Science 62: 5312-5316.

Hermann, J-M. 1999. Heterogeneous photocatalysis: fundamentals and applications to the removal of various types of aqueous pollutants. Catalysis Today 43: 115-129.

Ould-Mame, S.M., Zahraa, O., Bouchy, M. 2000. Photocatalytic degradation of salicylic acid on fixed $\mathrm{TiO}_{2}$ - kinetic studies. International Journal of Photoenergy 2: 59-66.

Van Gerven, T., Mul, G., Moulijn J., Stankiewicz, A. 2007. A review of intensification of photocatalytic processes. Chemical. Enginnering and Processing 46: 781-789.

Zahraa, O., Sauvanaud, L., Hamard, G., Bouchy, M. 2003. Kinetics of atrazine degradation by photocatalytic process in aqueous solution. International Journal of Photoenergy 2: 87-93. 